\title{
The ameliorative effect of lutein on ovarian ischemia- reperfusion injury in rats
}

\author{
Turkler $\mathrm{C}^{1}$, Kulhan $\mathrm{NG}^{1}$, Ata $\mathrm{N}^{1}$, Kiremitli $\mathrm{T}^{1}$, Keskin Cimen $\mathrm{F}^{2}$, Suleyman $\mathrm{H}^{3}$ \\ Erzincan University Medical Faculty, Gynaecology and Obstetrics Department, Erzincan, Turkey. \\ dr_canturkler@yahoo.com
}

\section{ABSTRACT}

OBJECTIVES: The aim of our study is to investigate biochemical and histopathological effects of lutein on the ovarian ischemia-reperfusion (I/R) injury in rats.

BACKGROUND: Reactive oxygen species and cytokines have a very important role in the pathogenesis of $I / R$ injury. Lutein and its derivatives may show an anti-inflammatory effect in relation to the decrease in inflammatory cytokines and increase in antioxidant enzymes.

METHODS: Wistar albino female rats were randomly divided into three groups before surgery as follows: $1 / R$ group (IRG; $n=6$ ), $1 \mathrm{mg} / \mathrm{kg}$ lutein + I/R group (LIRG; $n=6$ ), and a healthy control group scheduled for a sham operation (SG; $n=6$ ). The condition of ovarian ischemia was created by vascular clips. After two hours, the ovary was reperfused. Then, cyclooxygenase-1, cyclooxygenase-2, malondialdehyde and total glutathione levels were examined in ovary tissues of rats.

RESULTS: As the results of our study demonstrated, in ovarian tissues of animals after I/R, there was an increase in the levels of malondialdehyde and cyclooxygenase-2, while total glutathione and cyclooxygenase-1 were decreased. At the same time, it has been observed however that these ratios are reversed in the LIRG group $(p<0.05)$.

CONCLUSION: Lutein ameliorates the I/R-induced ovarian injury in rats by its antioxidative and anti-inflammatory activities (Fig. 2, Ref. 39). Text in PDF www.elis.sk.

KEY WORDS: lutein, ischemia-reperfusion, rat, ovary.

\section{Introduction}

Ovarian torsion is a common gynecological emergency occurring mostly in women at reproductive age, especially in first three decades (1). Surgical detorsion might be considered to restore the ovarian blood supply and reperfuse the ovarian tissue (2). The damage that occurs in the tissue after its reperfusion may sometimes be greater than that caused by ischemia. This process is known as ischemia-reperfusion ( $\mathrm{I} / \mathrm{R}$ ) injury (3).

$\mathrm{I} / \mathrm{R}$ injury happens because of proinflammatory polymorphonuclear leukocytes (PMNLs), neutrophils and thrombocytes which are carried by the blood to the ischemic tissue after reperfusion. The release of reactive oxygen species (ROS) and cytokines are very important factors in I/R injury $(4,5)$. ROS damage the tissue especially through lipid peroxidation. They affect cellular membrane lipids with lipid peroxidation and lead to the formation of malondialdehyde (MDA), which is a toxic product. MDA can

${ }^{1}$ Erzincan University Medical Faculty, Gynaecology and Obstetrics Department, Erzincan, Turkey, ${ }^{2}$ Erzincan University Medical Faculty, Pathology Department, Erzincan, Turkey, and ${ }^{3}$ Erzincan University Medical Faculty, Pharmacology Department, Erzincan, Turkey

Address for correspondence: C. Turkler, Menderes Mah. 127. Sok, No: 7 D Blok D:4 Nar Konutlari, Demirkent, Erzincan, 24100 Turkey. Phone: +90.446.2122216, Fax: +90.446.2122211 damage both membrane structure and functions of the cell (6). Some antioxidant enzymes such as catalase (CAT), superoxide dismutase (SOD), and glutathione peroxidase (GPx) or nonezymatic compounds such as glutathione (GSH), ascorbic acid (AA), and a-tocopherol protect the tissue from oxidative injury (7). The balance of ROS and antioxidants identifies the severity of oxidative stress (8).

Prostoglandins (PGs) play a very important role in the I/Rrelated inflammation. Cyclooxygenase (COX) is the main enzyme in the synthesis of these PGs (9). Cyclooxygenase-1 (COX-1) and cyclooxygenase-2 (COX-2) are the most common isoenzymes. The purpose of COX-1 is to protect the normal cell activity and cytoprotective activity in tissues. On the other hand, COX-2 rapidly increases in pathological conditions and induces the synthesis of proinflammatory PGs (10).

Lutein is a carotenoid synthesized by plants, bacteria, and algae. It is not synthesized in the body (11). High plasma carotenoid concentrations have been associated with a reduced risk of developing chronic disease (12). Studies have shown that diets high in lutein may be associated with a reduced risk of age-related macular degeneration (13). Also, lutein inhibits proliferation of prostate carcinoma cells in rats (14). However, the effect of lutein on ovarian $\mathrm{I} / \mathrm{R}$ injury has not been yet reported in literature. Therefore, the target of our study is to investigate the biochemical and histopathological effects of lutein on the ovarian I/R injury in a rat study. 


\section{3-717}

\section{Materials and methods}

Animals

Experimental animals were obtained from Ataturk University, Medical Experimental Application and Research Center. A total of eighteen Wistar albino female rats weighing 237 243 grams were randomly selected to be used in the experiment. Animals were housed and fed at normal room temperature $\left(22{ }^{\circ} \mathrm{C}\right)$ prior to the experiment. The study was conducted at Ataturk University, Experimental Studies and Research Center, Erzurum. The experimental procedure was approved by the Committee for Animal Research of Ataturk University, Erzurum. This study was carried out in accordance with international guidelines on the ethical use of animals (Ethics Committee Number: (04.04.2018/1800109522).

\section{Experimental groups}

Rats were randomly divided into three groups before experiment as follows: I/R group (IRG; $\mathrm{n}=6$ ), $1 \mathrm{mg} / \mathrm{kg}$ lutein $+\mathrm{I} / \mathrm{R}$ group (LIRG; $\mathrm{n}=6$ ), and a healthy control group scheduled for a sham operation $(\mathrm{SG} ; \mathrm{n}=6)$.

\section{Surgical and pharmacological procedures}

All surgical procedures were performed under sterile conditions in a proper laboratory setting. All rats were administered 25 $\mathrm{mg} / \mathrm{kg}$ intraperitoneal (i.p.) thiopental sodium anesthesia and then the ovaries were visualized by a 2-2.5 incision in the lower abdomen under anesthesia. Vascular clips were applied on the lower parts of the right ovaries of the rats in IRG and LIRG groups. Then, 2-hour ischemia followed by 2-hour reperfusion was performed. The thiopental sodium used in the experiment was provided from Ibrahim Etem Ulagay (Istanbul, Turkey). Lutein, supplied from Solgar (USA), was given perorally at a dose of $1 \mathrm{mg} / \mathrm{kg}$ to LIRG group $1 \mathrm{~h}$ before the application of reperfusion in the LIRG group. At the same time, the same volume of saline $(0.9 \% \mathrm{NaCl})$ was applied to IRG and SG rat groups by oral route. Ovaries in the SG group were not subjected to these processes. After these processes, rats were euthanized, and their right ovaries were removed for biochemical and histopathological examination. The results were compared among the groups.

\section{Biochemical analysis of MDA and total GSH (tGSH)}

MDA measurements were based on the method used by Ohkawa et al. involving spectrophotometrical measurement at 532 $\mathrm{nm}$ of absorbance of the pink-colored complex formed by thiobarbituric acid and MDA (15). The results were expressed as micromole/mg protein.

tGSH levels in ovarian tissues were measured according to the method defined by Sedlak J and Lindsay RH (16). DTNB (5,5'-dithiobis [2-nitrobenzoic acid]) disulfide is chromogenic in the medium, and DTNB is reduced easily by sulfhydryl groups. The yellow color produced during the reduction is measured by spectrophotometry at $412 \mathrm{~nm}$. The results were expressed as $\mu \mathrm{mol}$ /mg protein.

\section{Measurement of COX activity}

Measurements were performed according to the method of Kulmacz and Lands (17). Firstly, the analysis buffer and arachidonic acid solution were prepared. The other substances used were COX standard, colorimetric substrate, DuP697 (COX-2 inhibitor), and SC-560 (COX-1 inhibitor), which are available in commercial kits. Then, absorbances at a wavelength of $590 \mathrm{~nm}$ were read. The activity of COX in the tissue was expressed as nmol/min/mg protein (U/mg protein).

\section{Histopathological analysis}

Histological examination was performed at the pathology department of Erzincan University Hospital. After removal of the ovaries, samples were fixed in $10 \%$ formaldehyde, dehydrated in ethanol, and embedded in paraffin. The tissues were cut into 4-6- $\mu$ m-thick sections, which were deparaffinized with xylene and rehydrated with alcohol and water. Sections were stained with hematoxylin and eosin (H\&E) and examined under a microscope (Olympus pX53, Olympus Optical Co., Tokyo, Japan) with a digital camera system (Olympus UTVO.5XG-3, Olympus Optical Co., Tokyo, Japan) by a pathologist blinded to the study. Ovarian damage, including follicular cell degeneration, vascular congestion, hemorrhage, and inflammation (neutrophil infiltration), was evaluated histologically.

\section{Statistical analysis}

The software SPSS 16.0 was employed for the statistical analysis (SPSS Inc., Chicago, IL). Descriptive statistical results such as mean and standard deviation were obtained. Differences among the three groups were evaluated with Tukey analysis. The value of $\mathrm{p}<0.05$ was considered statistically significant.

\section{Results}

The MDA level in the ovarian tissue was $9.0 \pm 0.3 \mu \mathrm{mol} / \mathrm{mg}$ protein in $\mathrm{SG}$ group and $31.5 \pm 3.9 \mu \mathrm{mol} / \mathrm{mg}$ protein in IRG group.

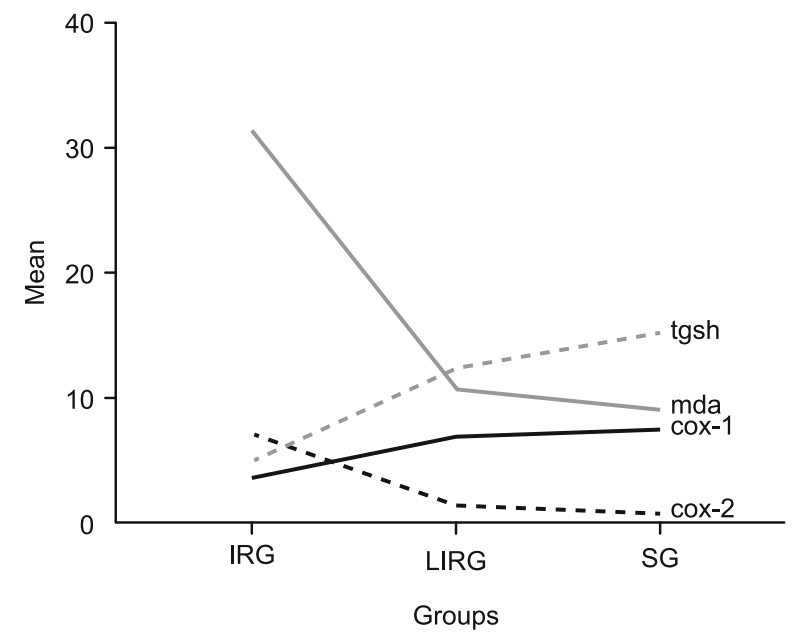

Fig. 1. COX-1, COX-2, MDA, and tGSH levels between groups. 

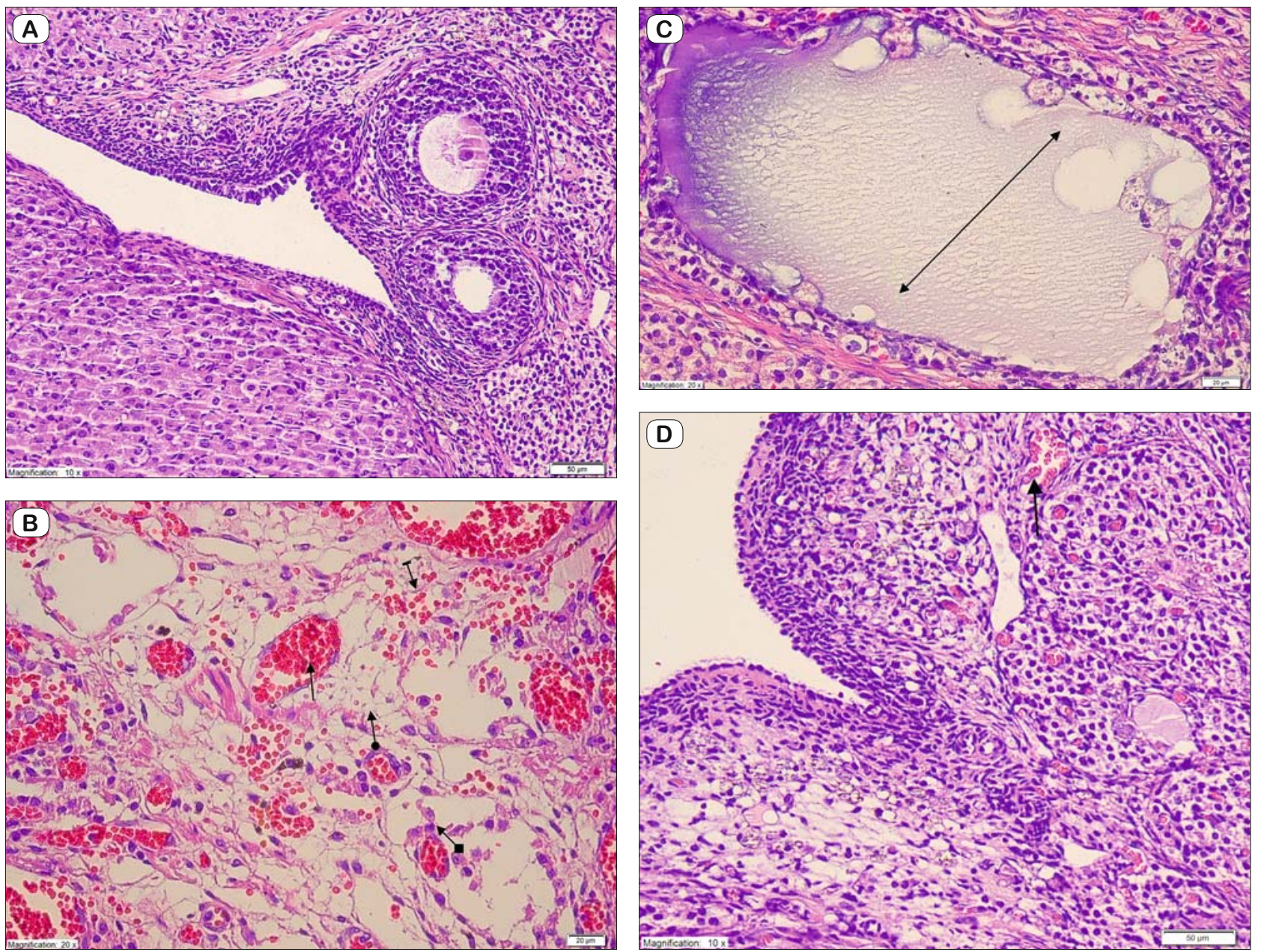

Fig. 2. Hematoxylin \& eosin (H\&E) sections from a single rat ovary of each group. (A) Sections of ovarian tissue showing secondary follicle in the healthy control group with sham operation (SG) (H\&E X200). (B) Ovarian tissue in the ischemia-reperfusion (IRG) group showing polymorphonuclear leukocytes (PMNLs; arrow with square at the edge), dilated congested blood vessel (arrow), hemorrhage (arrow with line at the edge) and edema (arrow with circle at the edge) (H\&E X400). (C) Ovarian tissue in the IRG group showing degenerated secondary follicle (double-headed arrow) (H\&E X400). (D) Ovarian tissue with almost normal appearance except for dilated congested blood vessels (arrow) in the $1 \mathrm{mg} / \mathrm{kg}$ lutein+ischemia-reperfusion group (LIRG) (H\&E X200).

When compared to the SG group, the increase in MDA level in IRG group was significant $(\mathrm{p}<0.05)$. The dose of $1 \mathrm{mg} / \mathrm{kg}$ lutein reduced the level of MDA $(10.8 \pm 1.4 \mu \mathrm{mol} / \mathrm{mg}$ protein) significantly compared to the IRG group $(\mathrm{p}<0.05)$. On the other hand, the $I / R$ process caused a significant decrease in tGSH level in the ovarian tissue of rats compared to the $\mathrm{SG}$ group $(\mathrm{p}<0.05)$. It was measured as $15.1 \pm 2.3 \mu \mathrm{mol} / \mathrm{mg}$ protein in $\mathrm{SG}$ group and $5.0 \pm 0.5$ $\mu \mathrm{mol} / \mathrm{mg}$ protein in IRG group. The dose of $1 \mathrm{mg} / \mathrm{kg}$ lutein significantly ameliorated the tGSH level $(12.3 \pm 2.4 \mu \mathrm{mol} / \mathrm{mg}$ protein $)$ in LIRG group when compared to IRG group $(\mathrm{p}<0.05)$ (Fig. 1).

As seen in Figure 1, the COX-1 activity was suppressed in IRG group compared to $\mathrm{SG}$ group $(3.7 \pm 0.3 \mathrm{U} / \mathrm{mg}$ protein vs $7.3 \pm 0.3 \mathrm{U} / \mathrm{mg}$ protein) and this was significant $(\mathrm{p}<0.05)$. But a significant increase $(6.9 \pm 0.2 \mathrm{U} / \mathrm{mg}$ protein) was found in LIRG compared to the IRG group ( $\mathrm{p}<0.05)$. On the contrary, COX-2 activity was significantly increased in IRG group when compared to $\mathrm{SG}$ group $(7.0 \pm 0.5 \mathrm{U} / \mathrm{mg}$ protein vs. $0.7 \pm 0.0 \mathrm{U} / \mathrm{mg}$ protein $)$ while the dose of $1 \mathrm{mg} / \mathrm{kg}$ lutein significantly decreased COX-2 activity $(1.4 \pm 0.2 \mathrm{U} / \mathrm{mg}$ protein; $\mathrm{p}<0.05)$.

The results of our study demonstrated that in ovarian tissues of animals administered with $\mathrm{I} / \mathrm{R}$, there was an increase in the levels of MDA and COX-2, and decrease in those of tGSH and COX-1, while these ratios were observed to be reversed in the LIRG group.

In histopathologic evaluation, normal histopathological appearance and secondary follicle were observed in the ovarian tissue of the SG group (Fig. 2A). Also, PMNLs, dilated congested blood vessels, hemorrhage, and edema were markedly seen in the ovarian tissue in IRG group (Fig. 2B). Degenerated secondary follicles were seen in the ovarian tissue in the IRG group (Fig. 2C). On the other hand, the dose of $1 \mathrm{mg} / \mathrm{kg}$ lutein corrected the pathological signs, only except for dilated congested blood vessels caused by 
I/R. Ovarian tissue with almost normal morphology in the LIRG group is shown in Figure 2D.

\section{Discussion}

Lutein is one of 600 known naturally occurring carotenoids (18). The mechanism by which carotenoids affect the risk of developing chronic disease is not clear but the risk reduction typically depends on anti-inflammatory and antioxidant effects (12, 19). Lutein ameliorated acute inflammation in rats by inhibiting the production of nitrites, MDA, PGE2, tumor necrosis factor alpha (TNF- $\alpha$ ), and interleukin 6 (IL-6) cytokines. The anti-inflammatory mechanism of lutein might be related to the decrease in inflammatory cytokines and increase in antioxidant enzymes (SOD, CAT, GPx, glutathione $\mathrm{S}$ transferase, glutathione reductase), which would result in the reduction of inducible nitric oxide synthase (iNOS), COX-2 and MDA and subsequent inflammatory responses (20).

There are numerous experimental drug studies about lutein. In these published studies, anti-inflammatory and antioxidative effects of lutein were investigated in several organs such as eye, prostate, kidney, liver, lung, and colon in animal models $(7,13$, $14,20-25)$. There are no data about the effect of lutein on I/Rrelated ovarian injury.

In the beginning of reperfusion following ischemia, approximately $70 \%$ of the oxygen provided to the tissue is oxidized to superoxide by xanthine oxidase (XO) (26). XO leads to the formation of excessive amounts of ROS (27). These ROS lead to the formation of toxic products such as aldehyde and MDA by oxidizing cell membrane lipids (28). GSH is one of the most important molecules of antioxidant capacity of the body that protect the tissues from ROS (29). In our study, I/R injury increased MDA levels and decreased the levels of tGSH in rat ovaries. Nevertheless, lutein significantly reduced MDA levels while significantly increasing the tGSH levels in rat ovaries injured by I/R.

Our results were in agreement with previous studies. For example, Cheng et al showed that lutein protects against skeletal muscle I/R injury by downregulating oxidative stress and inflammatory mechanisms (30). In another study, lutein was reported to have a beneficial effect against testicular I/R injury in rats (31). Additionally, the protective effect of lutein was demonstrated in small intestine and cardiac muscle $(32,33)$.

PGs synthesis is carried out via the COX pathway which contains two main isoenzymes named COX-1 and COX-2. COX-1 is involved in the synthesis of cytoprotective PGs, while COX-2 is induced by proinflammatory agents in pathological conditions (34, 35 ). Ibrahim et al. reported that $\mathrm{I} / \mathrm{R}$ injury increased the COX-2 activity in hepatic tissue, while COX-2 activity was found to be lower than that of COX-1 in healthy hepatic tissue in rats (36). With its anti-inflammatory property, we found that lutein decreased the COX-2 activity as well as increased the COX-1 activity in ovarian tissue injured by I/R. Also, we found the activity of COX-2 to be increased in IRG group compared to the healthy control group, while the activity of COX-1 was suppressed (Fig. 1).

Histopathological signs of hemorrhage, dilated congested blood vessels, PMNL infiltration, and degenerated follicles in the ovarian tissue of the IRG group were also observed in this study. Same histopathological changes in rat ovaries related to $\mathrm{I} / \mathrm{R}$ injury were shown in previous studies $(10,37,38)$. Lutein also ameliorated these histopathological changes in the ovaries of the rats from LIRG group in this study and when compared to the IRG group, we observed normal appearance except for dilated congested blood vessels.

Finally, Aksak Karamese et al reported that betacarotene, which is a kind of carotenoids, exerts protective effects on experimentally induced ovarian I/R injury. In this rat study, biochemical results (MDA, GSH) and histopathological evaluation after betacarotene administration were similar to those in our study (39).

There are some limitations to our study. Firstly, prior to this study, there have been no data about the effect of lutein on I/Rrelated ovarian injury. Secondly, as the aim of the study was to investigate if lutein had beneficial effects on ovarian I/R injury, only a single and average dose of $1 \mathrm{mg} / \mathrm{kg}$ was examined. It would be better to compare different doses of lutein to find the mean effective dose. Thirdly, I/R-related damage was demonstrated by histopathological changes in ovaries. This damage should be evaluated by infarction size or apoptosis in further studies. Fourthly, the results of experimental studies on animals should not be extrapolated to humans. We think that most accurate information will be reached in the future should more studies on this subject be done.

We detected the ameliorative effect of lutein on ovarian $\mathrm{I} / \mathrm{R}$ injury in rats. Because of this, lutein may be suggested to patients before detorsion surgery of ovaries. Nevertheless, further clinical studies are required to reach more accurate results.

\section{References}

1. Oelsner G, Cohen SB, Soriano D, Admon D, Mashiach S, Carp H. Minimal surgery for the twisted ischaemic adnexa can preserve ovarian function. Hum Reprod 2003; 18 (12): 2599-2602.

2. Hartley J, Akhtar M, Edi-Osagie E. Oophoropexy for Recurrent Ovarian Torsion. Case Rep Obstet Gynecol 2018; 2018: 8784958.

3. Carden DL, Granger DN. Pathophysiology of ischaemia-reperfusion injury. J Pathol 2000; 190: 255-266.

4. Yaman Tunc S, Agacayak E, Goruk NY et al. Protective effects of honokiol on ischemia/reperfusion injury of rat ovary: an experimental study. Drug Des Devel Ther 2016; 10: 1077-1083.

5. McMichael M, Moore RM. Ischemia-reperfusion injury pathophysiology, Part I. J Veter Emer Crit 2004; 14: 231.

6. Yapca OE, Borekci B, Suleyman H. Ischemia-reperfusion damage. Eurasian J Med 2013; 45: 126-127.

7. Yasar M, Erdi I, Kaya B. The preventive effects of atorvastatin and $\mathrm{N}$-acetyl cysteine in experimentally induced ischemia-reperfusion injury in rats. Bratisl Lek Listy 2018; 119 (3): 167-174.

8. McCord JM. Oxygen-derived free radicals in postischemic tissue injury. N Engl J Med 1985; 312: 159-163.

9. Suleyman H, Demircan B, Karagöz Y. Anti-inflammatory and side effects of cyclooxygenase inhibitors. Pharmacol Rep 2007; 59: 247-258.

10. Nayki C, Nayki U, Keskin Cimen F et al. The effect of rutin on ovarian ischemia-reperfusion injury in a rat model. Gynecol Endocrinol 2018; (3): 1-6. 
11. Krinsky NI, Landrum JT, Bone RA. Biologic mechanisms of the protective role of lutein and zeaxanthin in the eye. Ann Rev Nutrit 2003; 23: 171-201.

12. Farwell WR, Michael Gaziano J, Norkus EP, Sesso HD. The relationship between total plasma carotenoids and risk factors for chronic disease among middle-aged and older men. Br J Nutr 2008; 100 (4): 883-889.

13. Richer S, Stiles W, Statkute $L$ et al. Doublemasked, placebo-controlled, randomized trial of lutein and antioxidant supplementation in the intervention of atrophic age-related macular degeneration: the veterans LAST study (Lutein Antioxidant Supplementation Trial). Optometry 2004; 75: 216-230.

14. Gunasekera RS, Sewgobind K, Desai S et al. Lycopene and lutein inhibit proliferation in rat prostate carcinoma cells. Nutr Cancer 2007; 58 (2): 171-177.

15. Ohkawa H, Ohishi N, Yagi K. Assay for lipid peroxides in animal tissues by thiobarbituric acid reaction. Anal Biochem 1979; 95: 351-358.

16. Sedlak J, Lindsay RH. Estimation of total, protein-bound, and nonprotein sulfhydryl groups in tissue with Ellman's reagent. Anal Biochem 1968; 25: 192-205.

17. Kulmacz RJ, Lands WEM. Requirements for hydroperoxide by the cyclooxygenase and peroxidase activities of prostaglandin $\mathrm{H}$ synthase. Prostaglandins 1983; 25: 531-540.

18. Crichton G, Elias M, Alkerwi A, Buckley J. Intake of lutein rich vegetables is associated with higher levels of physical activity. Nutrients 2015; 7 (9): 8058-8071.

19. Woodside J, McGrath A, Lyner N, McKinley M. Carotenoids and health in older people. Maturitas 2015; 80 (1): 63-68.

20. Nidhi B, Sharavana G, Ramaprasad TR, Vallikannan B. Lutein derived fragments exhibit higher antioxidant and anti-inflammatory properties than lutein in lipopolysaccharide induced inflammation in rats. Food Funct 2015; 6 (2): 450-460.

21. AbuBakr HO, Aljuaydi SH, Abou-Zeid SM, El-Bahrawy A. Burn induced multiple organ injury and protective effect of lutein in rats. Inflammation 2018; 41 (3): 760-772.

22. Lakshminarayana R, Raju M, Krishnakantha TP, Baskaran V. Enhanced lutein bioavailability by lyso-phosphatidylcholine in rats. Mol Cell Biochem 2006; 281 (1-2): 103-110.

23. Raju J, Swamy MV, Cooma I et al. Low doses of beta-carotene and lutein inhibit AOM induced rat colonic ACF formation but highdoses augment ACF incidence. Int J Cancer 2005; 113 (5): 798-802.

24. Karlina MV, Pozharitskaya ON, Shikov AN, Kosman VM, Makarova MN, Makarov VG. LC Method for quantification of lutein in rat plasma: validation, and application to a pharmacokinetic study. Chromatographia 2008; 68 (11): 949-954.

25. Chucair AJ, Rotstein NP, Sangiovanni JP, During A, Chew EY, Politi LE. Lutein and zeaxanthin protect photoreceptors from apoptosis induced by oxidative stress: relation with docosahexaenoic acid. Invest Ophthalmol Vis Sci 2007; 48 (11): 5168-5177.
26. Lindsay TF, Liauw S, Romaschin AD, Walker PM. The effect of ischemia/reperfusion on adenine nucleotide metabolism and xanthine oxidase production in skeletal muscle. J Vasc Surg 1990; 12: 8-15.

27. Parks DA, Granger DN. Ischemia-induced vascular changes: role of xanthine oxidase and hydroxyl radicals. Am J Physiol 1983; 245 (2): G285-G289.

28. Del Maestro RF. An approach to free radicals in medicine and biology. Acta Physiol Scand Suppl 1980; 492: 153-168.

29. Bayir Y, Cadirci E, Polat B et al. Aliskiren - a promising strategy for ovarian ischemia/reperfusion injury protection in rats via RAAS. Gynecol Endocrinol 2016; 32: 675-683.

30. Cheng F, Zhang Q, Yan FF, Wan JF, Lin CS. Lutein protects against ischemia/reperfusion injury in rat skeletal muscle by modulating oxidative stress and inflammation. Immunopharmacol Immunotoxicol 2015; 37 (4): 329-334.

31. Al-Maghrebi M, Renno WM, Al-Somali HF, Botras MS, Qadhi IN. Lutein modulates transcription dysregulation of adhesion molecules and spermatogenesis transcription factors induced by testicular ischemia reperfusion injury: it could be SAFE. Naunyn Schmiedebergs Arch Pharmacol 2016; 389 (5): 539-551.

32. Sato Y, Kobayashi M, Itagaki S et al. Protective effect of lutein after ischemia-reperfusion in the small intestine. Food Chem. 2011; 127 (3): 893-898.

33. Adluri RS, Thirunavukkarasu M, Zhan L et al. Cardioprotective efficacy of a novel antioxidant mix VitaePro against ex vivo myocardial ischemia-reperfusion injury. Cell Biochem Biophys 2013; 67 (2): 281-286.

34. Yang S, Chou WP, Pei L. Effects of propofol on renal ischemia/reperfusion injury in rats. Exp Ther Med 2013; 6: 1177-1183.

35. Botting RM. Inhibitors of cyclooxygenases: mechanisms, selectivity and uses. J Physiol Pharmacol 2006; 57: 113-124.

36. Ibrahim MA, Abdel-Gaber SA, Amin EF, Ibrahim SA, Mohammed RK, Abdelrahman AM. Molecular mechanisms contributing to the protective effect of levosimendan in liver ischemia-reperfusion injury. Eur J Pharmacol 2014; 741: 64-73.

37. Unlubilgin E, Suleyman B, Balci G et al. Prevention of infertility induced by ovarian ischemia reperfusion injury by benidipine in rats: biochemical, gene expression, histopathological and immunohistochemical evaluation. J Gynecol Obstet Hum Reprod 2017; 46: 267-273.

38. Yapca OE, Kumbasar S, Salman S et al. Controlled reperfusion for different durations in the treatment of ischemia-reperfusion injury of the rat ovary: evaluation of biochemical features, molecular gene expression, and histopathology. Can J Physiol Pharmacol 2015; 93: 269-274.

39. Aksak Karamese S, Toktay E, Unal D, Selli J, Karamese M, Malkoc I. The protective effects of beta-carotene against ischemia/reperfusion injury in rat ovarian tissue. Acta Histochem 2015; 117 (8): 790-797.

Received June 15, 2018. Accepted August 7, 2018. 